\title{
Klasifikasi Kalimat Tanya Berdasarkan Taksonomi Bloom Menggunakan Support Vector Machine
}

\author{
Setio Basuki ${ }^{*}{ }^{*}$, Zakiyah Rakhmawati ${ }^{2}$, Galih Wasis Wicaksono ${ }^{3}$ \\ 1,2,3 Teknik Informatika/Universitas Muhammadiyah Malang \\ setiobasuki@umm.ac.id ${ }^{*}$, rakhma.zakiyah@webmail.umm.ac.id², galih.w.w@umm.ac.id.com³
}

\begin{abstract}
Abstrak
Klasifikasi adalah suatu teknik dalam melakukan kategori pada dokumen yang memiliki jumlah isi dokumen sangat banyak. Pada penelitian ini mengusulkan sebuah metode yang dapat menghasilkan klasifikasi kalimat tanya sesuai dengan level untuk ranah kognitif pada Taksonomi Bloom. Proses identifikasi soal dilakukan berdasarkan ekstraksi fitur sintaktik dan Bag-of-Words (BoW). Hasil dari ekstraksi fitur tersebut kemudian akan diklasifikasikan menggunakan algoritma klasifikasi SVM. Tugas akhir ini bertujuan untuk melakukan hasil klasifikasi kalimat tanya berdasarkan taksonomi bloom untuk ranah kognitif yang terbagi dalam 6 level yaitu, mengingat, memahami, menerapkan, menganalisis, mengevaluasi, dan membuat. Algoritma yang digunakan pada penelitian ini adalah Support Vector Machine (SVM). Algoritma tersebut dipilih karena mampu mengklasifikasikan data berdimensi tinggi yang dalam konteks tugas akhir ini adalah data berupa teks. Berdasarkan skenario pengujian yang sudah dilakukan, hasil rata-rata akurasi yang diperoleh pada proses pengklasifikasian kalimat menggunakan fitur sintaktik pada data uji sebesar $89.2 \%$, sedangkan untuk fitur Bag-of-Words (BoW) tingkat akurasi yang diperoleh sebesar $100 \%$. Berdasarkan hasil pengujian terhadap sistem klasifikasi yang telah dilakukan, rata-rata nilai akurasi didapatkan sangat baik, sehingga sistem dapat dikatakan atau layak untuk dikembangkan selanjutnya dengan berbagai variasi fitur atau algoritma pendukung lainnya.
\end{abstract}

Kata Kunci: Klasifikasi, Support Vector Machine, Taksonomi Bloom, Sintaktik, Bag Of Words

\begin{abstract}
Classification is a technique in the category of documents that have a lot of document content. In this study proposes a method that can generate the classification of sentences in accordance with the level for cognitive domain in Bloom's Taxonomy. The problem identification process is performed based on syntactic feature extraction and Bag-of-Words (BoW). The results of the feature extraction will then be classified using the SVM classification algorithm. This final project aims to perform the classification of sentences based on taxonomy of bloom for the cognitive domain which is divided into 6 levels namely, remembering, understanding, applying, analyzing, evaluating, and making. The algorithm used in this research is Support Vector Machine (SVM). The algorithm is chosen because it is able to classify high-dimensional data which in the context of this final task is text data. Based on the test scenario that has been done, the average result of accuracy obtained in the process of classification of sentences using syntactic features in the test data of $89.2 \%$, while for the Bag-of-Words (BoW) $100 \%$ accuracy rate is obtained. Based on the results of testing against the classification system that has been done, the average accuracy value obtained very well, so the system can be said or eligible to be developed further with variations of features or other supporting algorithms.
\end{abstract}

Keywords: Classification, Support Vector Machine, Bloom's Taxonomy, Syntax, Bag of Words

\section{Pendahuluan}

Sebagai penunjang dalam pembelajaran, siswa memiliki pegangan yaitu buku pelajaran untuk melakukan pelatihan dalam menyelesaikan setiap persoalan dalam soal.

Peraturan perundang-undangan telah disebutkan bahwa pedoman utama untuk menunjang siswa dalam melakukan proses pembelajaran terletak pada buku yang sudah disediakan oleh pengajar sebagai sumber paling utama pendukung siswa dalam belajar. [1] yang sudah melakukan praktik pada penelitiannya. Salah satu kelemahan yang ditemukan dalam penelitian [2] adalah rendahnya proporsi soal-soal dalam buku teks yang bertujuan agar siswa mampu menggunakan kemampuan penalaran mereka dalam mengerjakan atau menyelesaikan setiap soal yang diberikan oleh pendidik dalam semua kategori soal yang diberikan. Sehingga 
perlu dilakukan proses identifikasi terhadap kemampuan kognitif siswa untuk mengetahui sejauh mana pemahaman siswa terhadap pembelajaran yang sudah diajarkan. Hasil dari identifikasi tersebut nantinya yang akan dijadikan sebagai pedoman untuk dasar penilaian.

Taksonomi Bloom, terbagi menjadi tiga ranah ("domain"), yaitu ranah kognitif, ranah afektif dan ranah psikomotor. Untuk ranah kognitif Taksonomi Bloom, telah dilakukan perubahan yang mengakibatkan terjadi pemisahan antara pengetahuan dari proses kognitif. Sehingga, pada Taksonomi Bloom yang telah dilakukan perubahan, terbagi dalam dua dimensi yaitu dimensi pengetahuan dan dimensi proses kognitif [3]. Didakannya teknik pengklasifikasian ini bertujuan untuk memberikan kemudahan pada siswa dalam menyelesaikan setiap persoalan dalam soal berdasarkan tahapan untuk kategori soal termudah hingga tersulit. Pengklasifikasian pertanyaan tersebut menggunakan taksonomi pendidikan yang telah dilakukan oleh Bloom [4]. Menurut [5] menyatakan bahwa dalam praktiknya, tingkat kesulitan soal akan mengikuti hirarki taksonomi kognitif dari Bloom. Penulisan tugas akhir ini menggunakan salah satu algoritma klasifikasi yaitu Support Vector Machine (SVM). Support Vector Machine yaitu algoritma yang dalam klasifikasi bekerja pada prinsip linear classifier yang selanjutnya dikembangkan untuk dapat melakukan atau mengklasifikasi dalam persoalan yang non-linear. Pada penelitian [6] digunakan algoritma SVM untuk kategorisasi teks berbahasa Indonesia.

\section{Metode Penelitian}

\subsection{Studi Pustaka}

Mengumpulkan semua referensi dan memahami konsep dari system yang akan dibangun tentang studi kasus yang diambil, yaitu mengenai algoritma Support Vector Machine. Studi pustaka diperoleh dari berbagai referensi seperti jurnal, website resmi, dan laporan Tugas Akhir (TA), dsb.

\subsection{Persiapan Data}

Data yang disiapkan dalam tugas akhir ini yaitu kalimat tanya Berbahasa Indonesia, dimana kalimat tanya tersebut didapat dari soal-soal pada buku seperti Psikotes dan Lembar Kerja Siswa (LKS). Selain itu sebagai penunjang literatur pengambilan data yang lain, data kalimat tanya juga diambil dari situs bukusekolahdigital.com.

\subsection{Preprocessing Data}

Preprocessing Data dilakukan untuk membersihkan data kalimat tanya. Pada Gambar 1, yang dilakukan pada proses preprocessing data antara lain case folding, remove number \& punctuation serta tokenisasi.

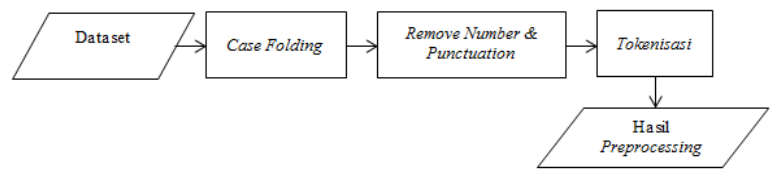

Gambar 1. Flowchart Sistem Preprocessing

\subsection{Ekstraksi Fitur}

Ekstraksi fitur dilakukan untuk mendapatkan karakteristik pembeda antar kelas untuk mempermudah proses klasifikasi. Fitur yang digunakan dalam penelitian ini adalah fitur sintaktik dan fitur bag of words.

\subsubsection{Fitur Sintaktik}

Fitur sintaktik adalah fitur dari sebuah soal yang diekstrak berdasarkan susunan kata pada soal tersebut [7]. Dalam penyusunan pola terhadap kalimat, terdapat beberapa kata kunci taksonomi bloom dan kata kunci pendukung lainnya yang dianalisis pada dataset untuk memperkuat hasil klasifikasi. Berikut beberapa daftar ekstraksi fitur pada Tabel 1.

Tabel 1. Daftar Ekstraksi Fitur Sintaktik

\begin{tabular}{ccc}
\hline No & Fitur & Deskripsi \\
\hline 1 & Kata WH & $<$ true, false $>$ Kata Kunci $5 \mathrm{~W}+1 \mathrm{H}$ \\
2 & Kata Kerja & $<$ true,false $>$ Kata Kunci Kerja \\
3 & Kata Perbandingan & $<$ true,false> Kata Kunci Perbandingan \\
\hline
\end{tabular}

REPOSITOR, Vol. 2, No. 4, April 2020: 427-436 
$4 \quad$ Kata Definisi

$5 \quad$ Kata Kausalitas

$6 \quad$ Kata Penyebutan

$7 \quad$ Kata Preposisi

$8 \quad$ Kata Penjelas

$9 \quad$ Kata Pilihan

10 Kata Tujuan

$11 \quad$ Kata Cara

12 Kata Waktu

13 Kata Tambahan

$14 \quad$ Kata Mengingat

$15 \quad$ Kata Memahami

16 Kata Menerapkan

$17 \quad$ Kata Menganalisis

18 Kata Mengevaluasi

19

20
Kata Membuat

Class
$<$ true,false $>$ Kata Kunci Definisi

$<$ true,false $>$ Kata Kunci Kausalitas

$<$ true,false $>$ Kata Kunci Penyebutan

$<$ true,false > Kata Kunci Preposisi

$<$ true,false > Kata Kunci Penjelas

$<$ true,false $>$ Kata Kunci Pilihan

$<$ true,false $>$ Kata Kunci Tujuan

$<$ true,false > Kata Kunci Cara

$<$ true,false $>$ Kata Kunci Waktu

$<$ true,false $>$ Kata Kunci Tambahan

$<$ true,false $>$ Kata Kunci Mengingat

$<$ true,false $>$ Kata Kunci Memahami

$<$ true,false > Kata Kunci Menerapkan

$<$ true,false $>$ Kata Kunci Menganalisis

$<$ true,false $>$ Kata Kunci Mengevaluasi

$<$ true,false $>$ Kata Kunci Membuat

$<$ nominal $>$ mengingat, memahami, menerapkan, menganalisis, mengevaluasi, membuat

\subsubsection{Fitur Leksikal (Bag of Words)}

Bag-of-Words adalah pemodelan yang dilakukan berdasarkan objek secara umum atau global seperti halnya kalimat teks atau dokumen yang digunakan sebagai bag atau dengan kata lain multiset kata tanpa melihat susunan tata bahasa maupun urutan kata untuk menjaga variasi kata [8]. Dengan kata lain, BoW merupakan sekumpulan kata-kata dalam teks dokumen untuk membentuk urutan agar dapat dihitung frekuensi kemunculan kata dalam domen tersebut. Tabel 2 merupakan contoh dari fitur Leksikal sebagai berikut.

Tabel 2. Ekstraksi Fitur

Kalimat : "jelaskan perbedaan kehidupan pada pranata penjara, pranata rumah sakit, dan pranata tempat pemukiman orang lanjut usia"

Fitur

Bag of Words

\section{Ekstraksi}

\{(jelaskan,1), (perbedaan,1), (kehidupan,1), (pada,1), (pranata,3), (penjara,1), (rumah,1), (sakit,1), (dan,1), (tempat,1), (pemukiman,1) , (orang, 1), (lanjut, 1), (usia, 1)\}

\subsection{Klasifikasi menggunakan Support Vector Machine}

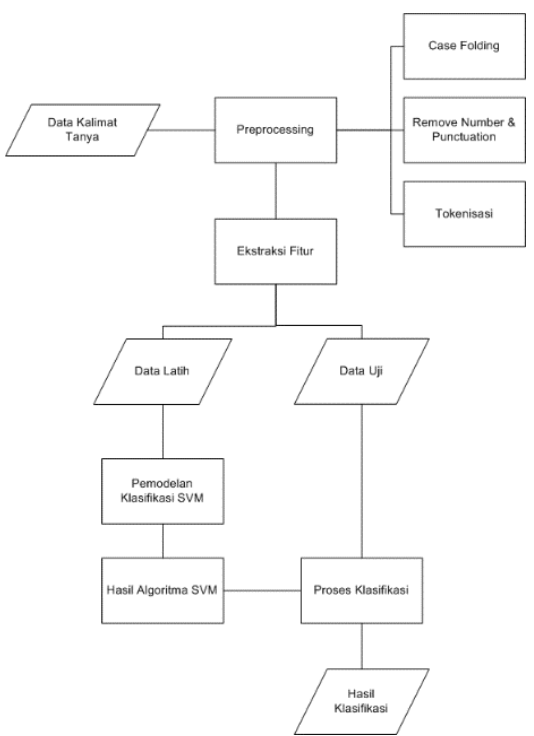

Gambar 2. Alur Sistem Klasifikasi 
Model klasifikasi yang digunakan pada tugas akhir ini yaitu menggunakan algoritma klasifikasi Support Vector Machine. Sebelum melakukan tahap klasifikasi dilakukan tahap preprocessing dan ekstraksi fitur, seperti pada Gambar 2.

Konsep SVM berusaha menemukan fungsi pemisah (hyperplane)untuk mencari bidang pemisah terbaik diantara fungsi yang tidak terbatas jumlahnya. Menemukan Hyperplane untuk mendapatkan pemisah terbaik antara kedua kelas dapat dilakukan dengan mengukur dari margin hyperplane tersebut agar dapat dicari titik maksimalnya. Adapun data yang berada pada bidang pembatas disebut support vector [9]. Pada dasarnya, konsep dasar dari algoritma SVM ditunjukkan pada Persamaan 1 dan Persamaan 2.

$$
\begin{gathered}
\min \frac{1}{2}|w|^{2} \\
\text { s.t } y_{i}\left(x_{i} \cdot w+b\right)-1 \geq 0
\end{gathered}
$$

dimana $\left(\mathrm{x}_{\mathrm{i}} \cdot \mathrm{w}+\mathrm{b}\right) \geq 1$ untuk kelas 1 , dan $\left(\mathrm{x}_{\mathrm{i}} \cdot \mathrm{w}+\mathrm{b}\right) \leq-1$ untuk kelas 2 ,

Keterangan:

$x_{i}$ adalah data set

$y_{i}$ adalah output dari data $x_{i}$, dan

$\mathrm{w}, \mathrm{b}$ adalah parameter yang dicari nilainya.

\subsection{Pengujian}

Pengujian yang dilakukan pada penelitian tugas akhir ini, yaitu pengujian terhadap hasil klasifikasi kalimat tanya berdasarkan target kelas. Tabel 3 berikut merupakan scenario pengujian.

Tabel 3. Skenario Pengujian

\begin{tabular}{ccc}
\hline Tahap & Parameter Pengujian & Parameter Data \\
\hline I & Data Latih & Kalimat Tanya \\
II & Hasil Klasifikasi & Kalimat Tanya \\
\hline
\end{tabular}

untuk setiap klasifikasi SVM di hitung nilai akurasinya dengan Persamaan 3.

$$
\begin{gathered}
\text { Accuracy }=\frac{T P+T N}{T P+F P+T N+F N} \\
\text { Precision }=\frac{T P}{T P+F P} \\
\text { Recall }=\frac{T P}{T P+F N}
\end{gathered}
$$

\section{Hasil Penelitian dan Pembahasan}

\subsection{Persiapan Data}

Pengerjaan tugas akhir ini data yang digunakan adalah kalimat tanya Berbahasa Indonesia, dimana kalimat tanya tersebut diambil dari soal-soal pada buku seperti Psikotes dan Lembar Kerja Siswa (LKS). Selain itu sebagai penunjang literatur pengambilan data yang lain, data kalimat tanya juga diambil dari situs bukusekolahdigital.com. Data yang terkumpul kemudian diklasifikasikan secara manual terlebih dahulu untuk mengetahui setiap target kelas dari masingmasing kalimat tanya. Jumlah data yang digunakan dalam penelitian \pm 600 data kalimat tanya dan data dari peneliti sebelumnya \pm 900 . Data tugas akhir disimpan dalam format Comma Separated Value (CSV). Berikut contoh dari data tugas akhir seperti pada Tabel 4.

\section{Tabel 4. Data Kalimat Tanya}

Identifikasikan sebab terjadinya kemajemukan oleh beragam suku bangsa yang tersebar di wilayah Indonesia?

Mengapa sifat unsur non logam semakin bertambah pada pergeseran dari kiri ke kanan dalam tabel periodik? Jelaskan!

Apakah situasi dan kondisi kehidupan masyarakat Indonesia dari hari ke hari kian memburuk merupakan salah satu dampak dari globalisasi? Kemukakan pendapatmu!

REPOSITOR, Vol. 2, No. 4, April 2020: 427-436 
Temukan perbedaan pelaksanaan Politik Bebas Aktif Indonesia sejak masa awal kemerdekaan hingga masa Reformasi!

Buktikan pernyataan bahwa Sosiologi merupakan ilmu sosial, bersifat heterogen, ilmu murni, dan abstrak!

Kelompokkan tumbuhan-tumbuhan dikotil dan monokotil berdasarkan persamaan dan perbedaan ciri yang dimiliki!

\subsection{Preprocessing Data}

Langkah pertama yang dilakukan sistem sebelum melakukan klasifikasi yaitu dilakukan pembersihan pada data kalimat tanya. Gambar 3 berikut merupakan hasil dari preprocessing data.

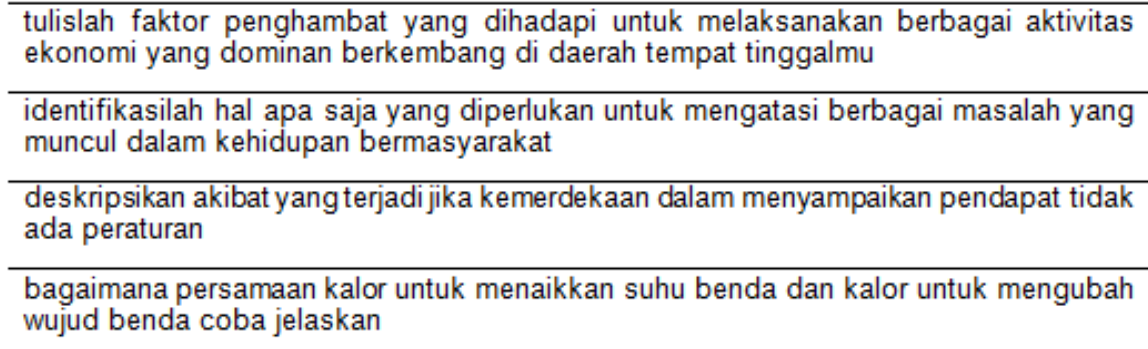

Gambar 3. Hasil Preprocessing Data

\subsection{Ekstraksi Fitur}

\subsubsection{Fitur Sintaktik}

Setelah selesai dilakukan proses pembersihan data, pengguna kemudian melakukan tahap ekstraksi fitur. Sebelum dilakukan ekstraksi fitur, pengguna terlebih dahulu melakukan pelabelan pada data kalimat tanya ke dalam beberapa target kelas taksonomi bloom untuk ranah kognitif. Pelabelan data tersebut dilakukan secara manual, dan setelah data selesai dilakukan pelabelan kemudian dapat disimpan dengan format *.csv. Gambar 4 berikut merupakan contoh data setelah dilakukan pelabelan.

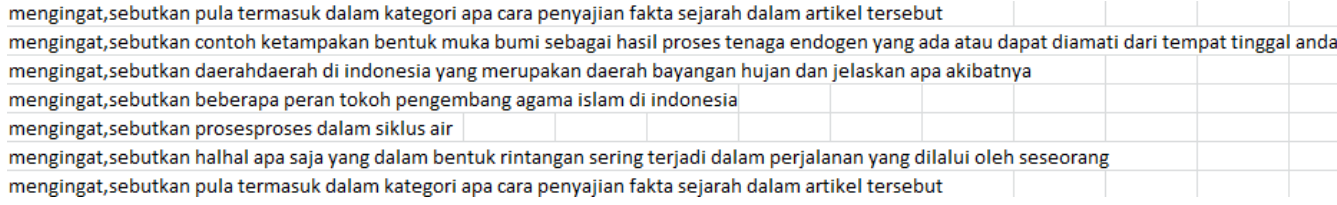

Gambar 4. Data Pelabelan Target Kelas

Ekstraksi fitur sintaktik digunakan 19 fitur untuk mengekstraksi kalimat agar mendapatkan hasil klasifikasi. Gambar 5 berikut merupakan hasil dari ekstraksi fitur Sintaktik.

\section{$1,1,0,0,0,0,1,0,0,0,1,0,1,1,1,1,0,1,1$, mengingat \\ $1,1,0,1,0,0,1,0,1,0,0,0,1,1,1,1,0,0,1$, mengingat \\ $1,1,0,1,0,0,1,0,0,0,0,0,1,1,1,1,0,0,0$, mengingat \\ $1,1,0,0,0,1,1,0,0,0,0,0,1,1,1,1,0,0,0$, mengingat \\ $0,1,0,0,0,0,1,0,0,0,0,0,1,1,1,1,0,0,0$, mengingat \\ $1,1,0,0,0,0,1,0,0,0,0,1,1,1,1,1,0,0,1$, mengingat \\ $1,1,0,0,0,0,1,0,0,0,1,0,1,1,1,1,0,1,1$, mengingat \\ Gambar 5. Hasil Data Ekstraksi Fitur Sintaktik}

\subsubsection{Fitur Leksikal (Bag of Words)}

Tahap ekstraksi fitur Bag-of-Words, untuk data awal berbeda dengan data awal yang ada pada ekstraksi fitur sintaktik. Dalam melakukan ekstraksi fitur untuk Bag-of-Words, data yang sudah terlabeli diubah dan disesuaikan dengan bentuk data dalam format *.arff. Berikut merupakan Gambar 6 contoh untuk data Bag-of-Words sebelum melakukan tahap ekstraksi. 


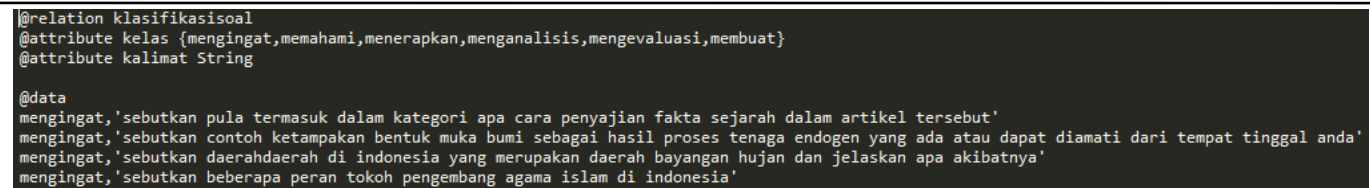

Gambar 6. Data Awal Bag-of-Words

Selanjutnya adalah proses filter terhadap dataset, yaitu tipe data pada data awal berbentuk String akan diubah menjadi bentuk Numeric. Proses pembentukan data tersebut sudah tersedia pada WEKA yaitu dengan keyword StringToWordVector. Gambar 7 merupakan hasil dari StringToWordVector.

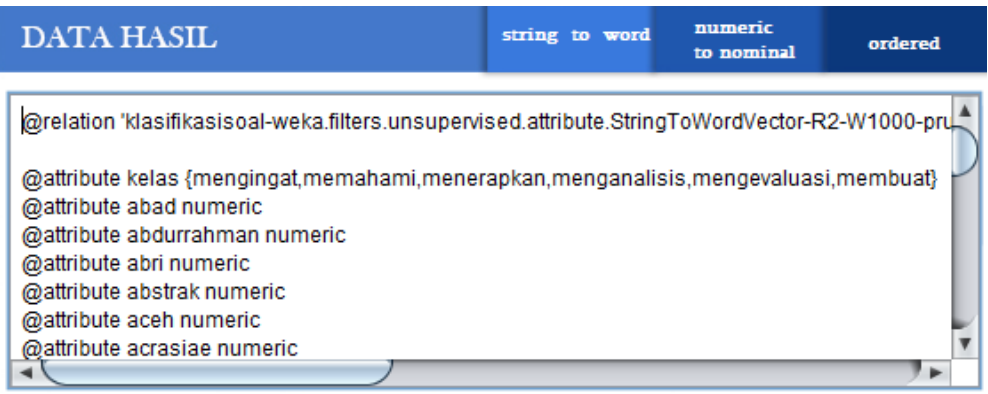

\section{Gambar 7. Hasil Filter StringToWordVector}

Setelah dilakukan filter StringToWordVector, kemudian dilakukan filter data NumericToNominal. Hal ini dkarenakan algoritma Support Vector Machine tidak mendukung tipe data numeric, sehingga perlu dilakukan filter data NumericToNominal. Gambar 8 dibawah ini menunjukkan hasil filter data NumericToNominal.

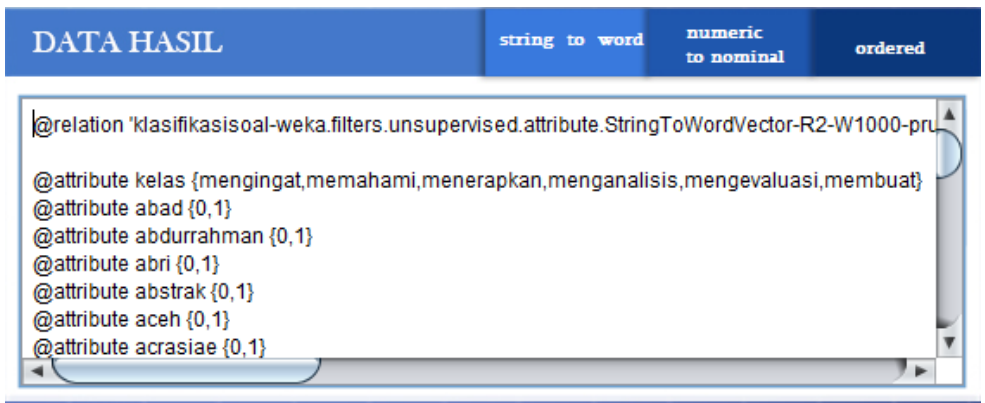

Gambar 8. Hasil Filter NumericToNominal

Setelah dilakukannya tahap filter NumericToNominal, tahap akhir dari proses ekstraksi fitur Bag-of-Words yaitu filter Ordered. Dimana pada tahap Ordered ini dilakukan untuk mengubah letak dari target kelas yang semula pada tahap NumericToNominal berada di attribute paling atas, dengan adanya filter Ordered ini attibute target kelas diubah ke attribute paling bawah untuk mempermudah algoritma melakukan klasifikasi nantinya. Berikut hasil filter data Ordered ditunjukkan pada Gambar 9.

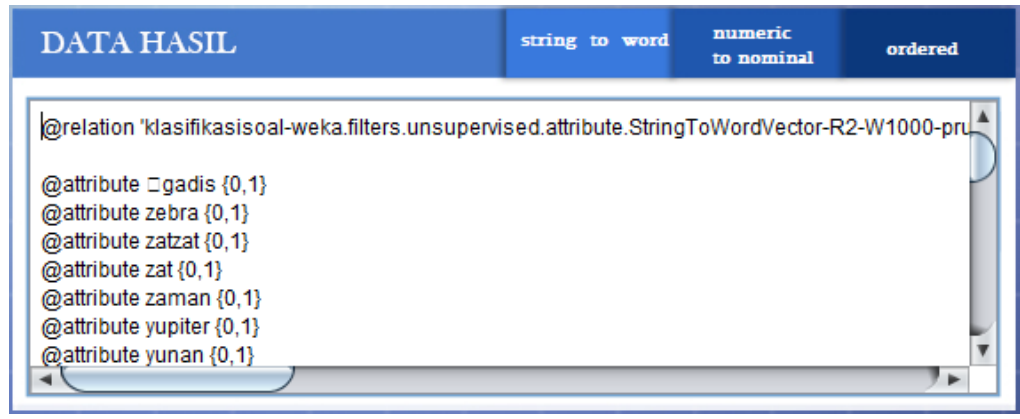

Gambar 9. Hasil Filter Ordered

REPOSITOR, Vol. 2, No. 4, April 2020: 427-436 


\subsection{Klasifikasi}

\subsubsection{Pembentukan Model dari Fitur Sintaktik dan Fitur Bag of Words}

Pengujian untuk model dari data train yang telah diekstraksi. Model tersebut dibentuk berdasarkan algoritma Support Vector Machine dan untuk melakukan pengujian terhadap model menggunakan K-Cross Validation dengan iterasi 10 kali. Gambar 10 dan Gambar 11 merupakan hasil pengujian model dari data train sebagai berikut.

\begin{tabular}{|c|c|c|}
\hline \multicolumn{3}{|l|}{ Cross Validation } \\
\hline Correctly Classified Instances & 769 & 80.1042 \% \\
\hline Incorrectly Classified Instances & 191 & 19.8958 \& \\
\hline Kappa statistic & 0.7613 & \\
\hline K\&B Relative Info Score & 34344.1907 ㅇํㅇ & \\
\hline K\&B Information Score & 887.7845 bits & $0.9248 \mathrm{bits} /$ ins tance \\
\hline Class complexity | order 0 & 2481.564 bits & $2.585 \mathrm{bits} /$ instance \\
\hline Class complexity | scheme & 2666.09 bits & $2.7772 \mathrm{bits} /$ instance \\
\hline Complexity improvement & -184.526 bits & $-0.1922 \mathrm{bits} /$ instance \\
\hline Mean absolute error & 0.2273 & \\
\hline Root mean squared error & 0.3178 & \\
\hline Relative absolute error & $81.8333 \%$ & \\
\hline Root relative squared error & $85.2623 \%$ & \\
\hline Total Number of Instances & 960 & \\
\hline
\end{tabular}

Gambar 10. Hasil Pengujian Data Latih Fitur Sintaktik

\begin{tabular}{|c|c|c|c|}
\hline \multicolumn{4}{|l|}{ Cross Validation } \\
\hline Correctly Classified Instances & 1164 & 97 & $\frac{8}{8}$ \\
\hline Incorrectly Classified Instances & 36 & 3 & $\frac{8}{8}$ \\
\hline Kappa statistic & 0.964 & & \\
\hline K\&B Relative Info Score & $45385.7423 \%$ & & \\
\hline K\&B Information Score & 1173.2044 bits & 0.9777 & bits/instance \\
\hline Class complexity | order 0 & 3101.955 bits & 2.585 & bits/instance \\
\hline Class complexity | scheme & 6221.6359 bits & 5.1847 & bits/ins tance \\
\hline Complexity improvement & -3119.6809 bits & -2.5997 & bits/instance \\
\hline Mean absolute error & 0.2238 & & \\
\hline Root mean squared error & 0.3126 & & \\
\hline Relative absolute error & 80.58 \& & & \\
\hline Root relative squared error & $83.8899 \%$ & & \\
\hline Total Number of Instances & 1200 & & \\
\hline
\end{tabular}

Gambar 11. Fitur Bag-of-Words

Berdasarkan hasil pengujian pada Gambar 12 dan Gambar 13, diperoleh hasil yang sangat baik dari jumlah data latih (data train) 480 data dengan nilai akurasi pada fitur sintaktik sebesar $80 \%$ dan nilai akurasi pada fitur Bag-of-Words sebesar $97 \%$.

\subsubsection{Pengujian Klasifikasi}

Pengujian klasifikasi dilakukan dengan memasukkan data uji sejumlah 120 data uji (data test) yang kemudian akan diuji dengan model yang sudah dibentuk untuk memperoleh hasil akurasi. Berikut merupakan hasil pengujian dari data uji yang telah dilakukan.

\begin{tabular}{|c|c|c|c|}
\hline \multicolumn{4}{|l|}{ Summary } \\
\hline Correctly Classified Instances & 107 & & $89.1667 \&$ \\
\hline Incorrectly Classified Instances & 13 & & $10.8333 \mathrm{~g}$ \\
\hline Kappa statistic & 0.87 & & \\
\hline K\&B Relative Info Score & 4448.2216 & 8 & \\
\hline $\begin{array}{l}\text { K\&B Information Score } \\
\text { bits/instance }\end{array}$ & 114.9849 & bits & 0.9582 \\
\hline $\begin{array}{l}\text { Class complexity | order } 0 \\
\text { bits/instance }\end{array}$ & 310.1955 & bits & 2.585 \\
\hline $\begin{array}{l}\text { Class complexity I scheme } \\
\text { bits/instance }\end{array}$ & 195.2106 & bits & 1.6268 \\
\hline $\begin{array}{l}\text { Complexity improvement } \\
\text { bits/instance }\end{array}$ & 114.9849 & bits & 0.9582 \\
\hline Mean absolute error & 0.225 & & \\
\hline Root mean squared error & 0.314 & & \\
\hline Relative absolute error & 81 & 8 & \\
\hline Root relative squared error & 84.243 & 8 & \\
\hline Total Number of Instances & 120 & & \\
\hline
\end{tabular}

Gambar 12. Hasil Pengujian Data Test Fitur Sintaktik 


\begin{tabular}{|c|c|c|c|c|}
\hline \multicolumn{5}{|l|}{ Summary } \\
\hline Correctly Classified Instances & 120 & & 100 & 8 \\
\hline Incorrectly Classified Instances & 0 & & 0 & 8 \\
\hline Kappa statistic & 1 & & & \\
\hline K\&B Relative Info Score & 4642.2337 & 8 & & \\
\hline $\begin{array}{l}\text { K\&B Information Score } \\
\text { bits/instance }\end{array}$ & 120 & bits & 1 & \\
\hline $\begin{array}{l}\text { Class complexity I order } 0 \\
\text { bits/instance }\end{array}$ & 310.1955 & bits & 2.585 & \\
\hline $\begin{array}{l}\text { Class complexity | scheme } \\
\text { bits/instance }\end{array}$ & 190.1955 & bits & 1.585 & \\
\hline $\begin{array}{l}\text { Complexity improvement } \\
\text { bits/instance }\end{array}$ & 120 & bits & 1 & \\
\hline Mean absolute error & 0.2222 & & & \\
\hline Root mean squared error & 0.3103 & & & \\
\hline Relative absolute error & 80 & 8 & & \\
\hline Root relative squared error & 83.2613 & \& & & \\
\hline Total Number of Instances & 120 & & & \\
\hline
\end{tabular}

\section{Gambar 13. Fitur Bag-of-Words}

Mendapatkan akurasi, precision, dan recall harus diketahui confusion matrix dari hasil klasifikasi. Berikut Confusion Matrix dari hasil klasifikasi untuk masing-masing fitur:

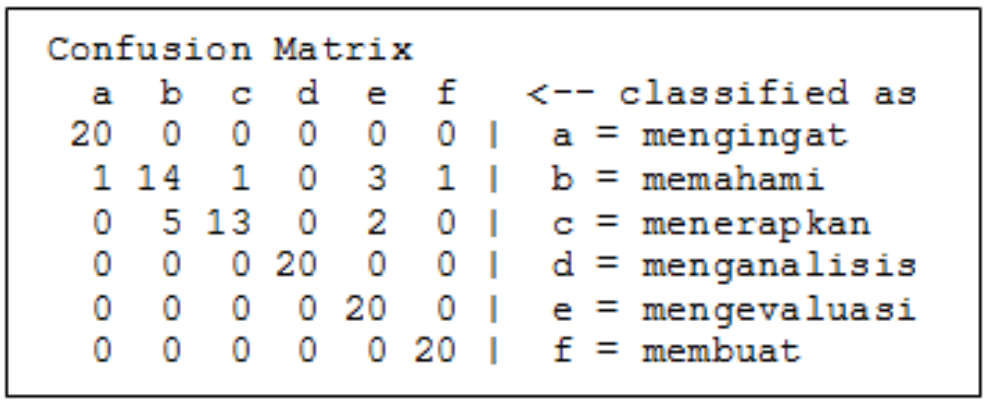

Gambar 14. Confusion Matrix Tes Klasifikasi Fitur Sintaktik

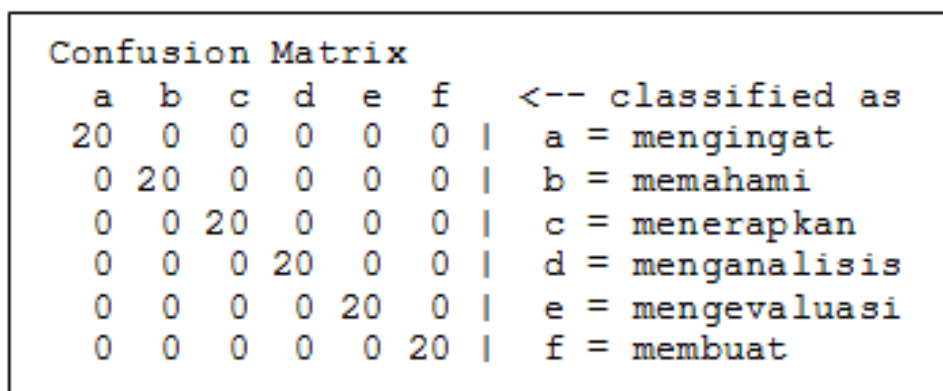

Gambar 15. Fitur Bag of Words

Berdasarkan Gambar 14 dan Gambar 15 hasil confusion matrix diatas, maka dapat diketahui hasil dari akurasi, precision, dan recall dari masing-masing target kelas. Berikut merupakan Tabel 5 dan Tabel 6, detail dari hasil akurasi, precision dan recall.

Tabel 5. Detail Akurasi Tes Klasifikasi Fitur Sintaktik

$===$ Detailed Accuracy By Class ===

$\begin{array}{cccccccc}\text { TP Rate FP Rate Precision } & \text { Recall } & \text { F-Measure ROC Area Class } \\ 1 & 0.01 & 0.952 & 1 & 0.976 & 0.995 & \text { mengingat } \\ 0.7 & 0.05 & 0.737 & 0.7 & 0.718 & 0.894 & \text { memahami } \\ 0.65 & 0.01 & 0.929 & 0.65 & 0.765 & 0.905 & \text { menerapkan } \\ 1 & 0 & 1 & 1 & 1 & 1 & \text { menganalisis } \\ 1 & 0.05 & 0.8 & 1 & 0.889 & 0.975 & \text { mengevaluasi } \\ 1 & 0.01 & 0.952 & 1 & 0.976 & 0.995 & \text { membuat } \\ \text { Avg. } & 0.892 & 0.022 & 0.895 & 0.892 & 0.887 & 0.961 \\ \text { d }\end{array}$

REPOSITOR, Vol. 2, No. 4, April 2020: 427-436 


\begin{tabular}{ccccccc} 
TP Rate & FP Rate & \multicolumn{2}{c}{ Precision } & \multicolumn{2}{c}{ Recall } & F-Measure ROC Area Class \\
1 & 0 & 1 & 1 & 1 & 1 & mengingat \\
1 & 0 & 1 & 1 & 1 & 1 & memahami \\
1 & 0 & 1 & 1 & 1 & 1 & menerapkan \\
1 & 0 & 1 & 1 & 1 & 1 & menganalisis \\
1 & 0 & 1 & 1 & 1 & 1 & mengevaluasi \\
1 & 0 & 1 & 1 & 1 & 1 & membuat \\
Weighted Avg. & 1 & 0 & 1 & 1 & 1 & 1 \\
\hline
\end{tabular}

\section{Kesimpulan}

Berdasarkan hasil pengujian klasifikasi yang sudah dilakukan dengan metode Support Vector Machine (SVM) menunjukkan bahwa hasil akurasi, presisi, dan recall pada masing-masing fitur yaitu fitur sintaktik dan fitur Bag-of-Words memberikan hasil akurasi yang cukup baik, sehingga dapat diambil kesimpulan dari pengerjaan tugas akhir ini, klasifikasi kalimat tanya berdasarkan taksonomi bloom menggunakan support vector machine (SVM) sistem dan model yang telah dibangun dapat bekerja secara optimal. Berikut beberapa pembahasan dari tugas akhir ini antara lain:

1. Berdasarkan hasil pengujian dari 600 dataset, 120 data digunakan sebagai data uji (data test).

2. Pada proses pengujian klasifikasi dilakukan 2 jenis pengujian yaitu pengujian akurasi menggunakan fitur sintaktik dan pengujian akurasi menggunakan fitur Bag-of-Words.

3. Hasil akurasi masing-masing fitur berbeda, pada pengujian menggunakan ekstraksi fitur sintaktik diperoleh hasil akurasi, precision, dan recall sebesar $89.2 \%$, $89.5 \%$, dan $89.2 \%$. Sedangkan untuk pengujian menggunakan fitur Bag-of-Words diperoleh hasil akurasi, precision, dan recall sebesar $100 \%, 100 \%$, dan $100 \%$.

4. Dari hasil akurasi yang diperoleh pada masing-masing fitur, dapat disimpulkan bahwa pembuatan model pada algoritma Support Vector Machine memiliki kelayakan sangat baik dalam melakukan klasifikasi data berupa teks.

Pengembangan pada penelitian selanjutnya, diharapkan kalimat tanya tidak hanya diklasifikasikan kedalam ranah kognitif saja, tetapi dapat dikembangkan untuk klasifikasi pada ranah afektif dan psikomotor, sehingga semua ranah pada konsep Taksonomi Bloom dapat diklasifikasikan berdasarkan tingkat kesulitan pada masing-masing penyusun hierarkinya.

\section{Referensi}

[1] C. H. Giani, Zulkardi, "Analisis Tingkat Kogniitf Soal-Soal Buku Teks Matematika Kelas Vii Berdasarkan Taksonomi Bloom," vol. 1, 2012.

[2] A. Masduki. Subandriah, M.R. Irawan, D.Y. Prihantoro, "Level Kognitif soal-soal Pada Buku Teks Matematika SMP Kelas VII," 2013.

[3] T. T. Pembelajaran, "Taksonomi Tujuan Pembelajaran Ari Widodo Jurusan Pendidikan Biologi FPMIPA - Universitas Pendidikan Indonesia JI . Dr. Setiabudhi 229 Bandung Email : widodo@upi.edu September 2005 Dari penulis Furst, Hill dan Krathwohl ( 1956 ), sudah sejak lama digunak," vol. 4, pp. 61-69, 2005.

[4] A. H. Nasrulloh, "'Analisis Tingkat Kognitif Tes Kompetensi pada Buku Sekolah Elektronik (Bse) Matematika Smp/Mts Kelas IX berdasarkan Berdasarkan Taksonomi Bloom,"' 2011.

[5] A. Sudarsyah, "Manajemen Implementasi Kurikulum: Sisi Lain Ujian Nasional," 2013. [Online]. Available: http://m.kompasiana.com/post/re ad/543693/1/sisi-I.

[6] D. Wulandini, F., "A Study on Text Classification for Webmining Based Spatio Temporal Analysis of the Spread of Tropical Diseases.," 2010.

[7] B. Loni, "Enhanced Question Classification With Optimal Combination of Features. Delft University of Technology," 2011.

[8] "Bag of words model." [Online]. Available: http://en.wikipedia.org/wiki/Bag-of-words_model. [Accessed: 05-Dec-2014]

[9] D. Widiastuti, "Analisa Perbandingan Algoritma SVM, Naïve Bayes, dan Decission Tree dalam Mengklasifikasikan Serangan (Attack) pada Sistem Pendeteksi Intrusi," Dwi Widiastuti, p. 3, 2007. 
REPOSITOR, Vol. 2, No. 4, April 2020: 427-436 